\title{
Early selective attention effects on cutaneous and acoustic blink reflexes
}

\author{
STEVEN A. HACKLEY and FRANCES K. GRAHAM \\ University of Wisconsin, Madison, Wisconsin
}

\begin{abstract}
In two experiments, selective modulation of the human blink reflex was examined by directing subjects to judge duration of the startling or nonstartling member of an acoustic-cutaneous stimulus pair. The startling stimulus was acoustic in the first experiment and cutaneous in the second. In both experiments, magnitude and onset latency were facilitated when the subjects attended to rather than away from the reflex-eliciting stimulus, although changes in cutaneous reflex size were insignificant. However, a nonselective inhibition of blink magnitude on warned relative to unwarned trials, associated with latency facilitation of the cutaneous reflex, was a stronger effect. The existence of both selective, concordant and nonselective, discordant changes in latency and magnitude could not be explained by a single mechanism. Heart rate changes also suggested that warning initiated some process in addition to attention to intake. The predictability of warned events may play a larger role than has previously been recognized.
\end{abstract}

Can attention modulate the early phases of information processing or, instead, is the sensory processing of ignored stimuli identical to that of attended stimuli? Behavioral evidence has not been able to resolve the issue in favor of either earlyselection (Broadbent, 1958; Treisman, 1969) or lateselection theories (Deutsch \& Deutsch, 1963; Norman, 1968). Studies of evoked brain potentials in the human, however, have commonly supported the early-selection view (e.g., Desmedt \& Robertson, 1977; Eason, Oakley, \& Flowers, 1983; Hillyard, Hink, Schwent, \& Picton, 1973). The general finding has been that potentials evoked by stimuli toward which attention is directed differ from the potentials evoked by unattended stimuli as early as 50 to $100 \mathrm{msec}$. On the basis of such early differences, Hillyard (1981) interpreted the findings as being dependent upon a tonic prestimulus set rather than an active recognition of each stimulus, and Näätänen (1982) similarly suggested that a selective state was "already prevailing" at the moment of stimulus delivery. The state was assumed to produce a "temporary bias somewhere in the sensory system" (Näätänen, 1982, p. 629).

This research was supported by NIH Grant HD01490, by a Research Scientist award (K3-MH21762) to F.K.G., by a NSF predoctoral fellowship to S.A.H., and by a core support grant (HD03352) to the Waisman Center on Mental Retardation and Human Development. Experiment 1 was reported at the 21st annual meeting of the Society for Psychophysiological Research and in a master's thesis by S.A.H. We gratefully acknowledge the valuable contributions of Bruno Anthony during all phases of this study. Thanks are also extended to Christine Wang for technical assistance and to Bonnie Zeigler for many helpful suggestions. Address reprint requests to Frances K. Graham, Waisman Center on Mental Retardation, 1500 Highland Ave., University of Wisconsin, Madison, Wisconsin 53705.
Modulation of the polysynaptic blink reflex offers an alternative method for assessing early selectivity. The reflex has a latency as short as or shorter than that observed for modulated brain potentials and is elicited by stimulation in several modalities (Rimpel, Geyer, \& Hopf, 1982). If attention can selectively alter afferent pathways and those pathways comprise a portion of the reflex circuitry, the reflex should vary accordingly. A number of studies of the acoustic reflex have reported results congruent with early selection: Enhancement of blink magnitude has been found when attention was focused on the reflexelicting stimulus (Bohlin \& Graham, 1977; Bohlin, Graham, Silverstein, \& Hackley, 1981) or was directed toward a stimulus in the same modality (Anthony, 1981; Bauer, 1982; Putnam \& Meiss, 1981); conversely, when attention was directed toward a stimulus in another modality, acoustic blink magnitude was diminished (Anthony, 1981; Bauer, 1982; Putnam \& Meiss, 1980; Silverstein, Graham, \& Bohlin, 1981).

Stronger evidence that such effects involve early sensory modulation rather than some later nonspecific pattern of activation comes from a study in which both acoustic and visual blink-eliciting probes were delivered unpredictably to infants during foreground looking or listening conditions (Anthony \& Graham, 1983). If the looking condition, for example, produced nonselective facilitation in the portion of the reflex pathway following convergence of modality-specific sensory paths, then both acoustic and visual probes should have elicited enhanced blinks. The study, however, produced opposite patterns of results for the two reflexes.

The purpose of the present research was to confirm attentional modulation of the acoustic reflex and ex- 
tend the findings to the tactile modality. Two experiments employed the coincident-stimuli paradigm of Silverstein et al. (1981), in which a task-irrelevant and a task-relevant stimulus were presented at the same time, with only one of the two capable of eliciting a blink. In Experiment 1, an acoustic stimulus was reflex-eliciting and was paired with a weak tactile stimulus; in Experiment 2, the reflex-eliciting stimulus was tactile and the weak stimulus, acoustic. In both experiments, task relevance was determined by instructions to judge the duration of one stimulus and ignore the other; these instructions were reversed in counterbalanced halves of a session.

It was expected that, if task instructions could produce a preset sensory selective state, then attention directed toward the reflex-eliciting member of the stimulus pair should produce larger and, possibly, shorter latency blinks than attention directed away from the reflex stimulus and toward the weak stimulus. Although prior research had suggested that warning might shorten latency independently of any attention-directing effect (Bohlin et al., 1981), latency differences between attend-toward and attendaway conditions had not been directly compared in a within-subject design. It was also expected that any selective-attention effects would be greater under warned than under unwarned conditions if warning led to a period of phasic, presumably more focused attention. Heart rate deceleration was measured to verify that warning initiated a period of anticipation of stimulus intake (Lacey \& Lacey, 1970).

The reflex elicited by periorbital cutaneous stimulation was of special interest because it has two distinct components, an oligosynaptic component (R1), which occurs ipsilaterally with a latency of 10$12 \mathrm{msec}$, and a later polysynaptic blink reflex (R2), which occurs bilaterally with a latency of $30-40$ msec. The early component is frequently enhanced under conditions that reduce the later component (e.g., Boelhouwer, 1982; Kimura, 1973; Sanes \& Ison, 1979; Shahani \& Young, 1972), but the situations in which it has been investigated either have not employed a manipulation directing attention to the modality of the reflex-eliciting probe or attention has been directed away from the probe by warning of an imperative stimulus in a different modality. It was expected that, in the present research, the late component would show the same effects of warning and attention as the acoustic reflex. Predictions were not made with respect to effects on the early component, and, due to technical problems, only limited conclusions could be drawn.

\section{METHOD}

\section{Subjects}

Introductory psychology students, 9 male and 15 female in Experiment 1 and 16 male and 8 female in Experiment 2, received extra credit for serving as subjects. A preexperimental question- naire indicated that none had any known cardiovascular or serious hearing dysfunction. Seven subjects in Experiment 1 and three in Experiment 2 were replaced: six subjects had more than $67 \%$ zero or unscoreable blinks, one subject failed to follow task instructions, and equipment error occurred in three cases.

\section{Apparatus}

Subjects were seated in an electrically shielded sound-attenuated chamber (IAC Model 404-A) facing a $25 \times 5 \mathrm{~cm}$ panel, mounted on the wall at eye level, which displayed a fixation point and red and green light-emitting diodes whose illumination signaled the correctness of subject judgments. The subject chamber had an intercom connection with an adjacent equipment/control room.

Stimulus selection and timing were under the control of Iconix logic and a PDP-12 computer. Acoustic stimulus-generating equipment included a Hewlett-Packard (200 CDR) wide-range oscillator, gated on and off by an Iconix 1665 audio gate (Experiment 1) or a Medical Electronics Laboratory electronic switch (Experiment 2), and a Grason-Stadler noise generator (Model 901 , speech band). Stimulus tones of $800 \mathrm{~Hz}$ and continuous background noise were led through a mixer and a Grason-Stadler 1288 audio power amplifier and were delivered through matched circumaural (001A cushion) TDH-49 (Experiment 1) or Sharpe MKII (Experiment 2) earphones. Intensities were calibrated daily with a Bruel \& Kjaer 2203 sound-level meter, Type 4153 artificial ear, and a 4143 condenser microphone $(1.25 \mathrm{~cm})$. For Experiment 1, in which the tones were reflex-eliciting, the intensities were $103 \mathrm{~dB}(\mathrm{~A})$ re $20 \mu \mathrm{N} / \mathrm{m}^{2}$ over $62-\mathrm{dB}$ noise with a rise time of $1.5 \mathrm{msec}$ at the output of the phones; for Experiment 2, in which the tones were nonstartling, they were $69 \mathrm{~dB}$ over 76-dB noise and rise time was $78 \mathrm{msec}$ at the output of the phones. ${ }^{1}$

The cutaneous stimuli were generated by gating compressed air through a solenoid-controlled stopcock and air delivery system. For Experiment 1, in which the airpuff was nonstartling, the air was vented through a $5 \times 8 \mathrm{~mm}$ opening in a Styrofoam handrest. The vent lay below the third digit (left hand) in the center of a $5 \times$ $1.5 \mathrm{~cm}$ trough that was at right angles to the digit and thus distributed air flow to the adjacent fingers. The delivery system, consisting of Tygon tubing, two 200-ml reservoirs, and a constricting clamp, attenuated and smoothed pressure to produce a perceptible but near-threshold sensation without a measurable onset transient. Background noise was set to mask accompanying acoustic components. A preliminary study $(\mathrm{N}=18)$ had found that paired weak puff and loud tone did not elicit larger blinks $(M=180$ analog-to-digital units, or ADU) than tone alone $[\mathrm{M}=192 \mathrm{ADU}$; $t(17)=.95]$.

For Experiment 2, in which the airpuff was reflex-eliciting, the air was vented below the right eyebrow from a $1-\mathrm{cm}$ tube held in place by a headset and positioned to minimize air flow into the eye and nasal regions. Pressure was increased and the $200-\mathrm{ml}$ reservoirs were eliminated to produce a stronger stimulus with a rapid transient overshoot. These changes also introduced an acoustic component, which was reduced by lead pipe and mufflers in the delivery system and completely masked by changing earphones and increasing the background white noise. The remaining tactile component of the puff was psychophysically matched $(\mathrm{N}=4)$ to a $50-\mathrm{msec}, 800-\mathrm{Hz}$ tone at $88 \mathrm{~dB}$. A second preliminary study $(\mathrm{N}=$ 13) demonstrated that pairing weak tone with strong puff had no effect on blink size $(M=282$ ADU for puff alone and $M=282$ ADU for puff plus tone).

A 50-msec warning stimulus was provided by a plastic-sealed door buzzer, enclosed in a thickly padded box into which the subject's right hand was inserted. When activated by a Grass SD-5 stimulator, the buzzer produced a palpable vibration at $160 \mathrm{~Hz}$ with a distinct auditory component. Pilot subjects $(N=4)$ had matched the intensity of the buzzer's acoustic component to an 82 $\mathrm{dB}, 50-\mathrm{msec}, 800-\mathrm{Hz}$ tone and its tactile component to the same tone at $96 \mathrm{~dB}$.

The computer also controlled sampling of heart rate and eyeblink activity, which were continuously recorded on a Beckman Type $\mathbf{R}$ dynograph. The amplified electrocardiogram, from a lead 
II placement of Beckman Biopotential electrodes filled with Beckman electrode paste, was led through a Schmitt-trigger/oneshot combination that delivered a 1-msec pulse to the KW-12 clock input of the computer each time an $R$-wave was detected during the 10 -sec period from $7 \mathrm{sec}$ preonset of the coincident stimuli to $3 \mathrm{sec}$ postonset.

Bipolar electromyograms (EMG) were recorded from the pretarsal portion of $\mathrm{m}$. orbicularis oculi of both the left and right upper eyelids. Two minature (3-mm diam) surface electrodes (Silverstein \& Graham, 1978), filled with Beckman electrode paste, were attached with Blenderm tape (3M Co.) just above the eyelashes and centered about a point directly above the pupil, with a 4-mm interelectrode distance. Interelectrode impedance was $12 \mathrm{k} \Omega$ or less. Following amplification by a Princeton Applied Research Model 113 preamplifier (bandpass $10-10000 \mathrm{~Hz}$ ), the left-lid EMG was full-wave rectified and integrated (Beckman Type 9852A Direct-Average EMG integrator) and led through Beckman amplifiers with a $200-\mathrm{Hz}$ cutoff to the computer for digitization every millisecond for $250 \mathrm{msec}$, beginning with onset of the tone-puff pair. Sensitivity was adjusted for each subject to keep records within the 1023 ADU range of the computer's analog channel: Experiment 1 sensitivity averaged 2.35 times the sensitivity in Experiment 2. The right-lid EMG was treated similarly, except that it was full-wave rectified only (by a Medical Electronics Laboratory active rectifier), and system sensitivity was fixed at $.375 \mu \mathrm{V} / \mathrm{ADU}$.

\section{Procedure}

Half of the subjects in each experiment, randomly assigned, attended to the reflex-eliciting stimulus in the first half of the experiment and attended away from the reflex-eliciting stimulus in the second half; judgment order was reversed for the remaining subjects. After completion of a consent form and health questionnaire, written instructions informed the subjects that task stimuli would be "short" or "long," that they would be accompanied by a distracting stimulus (described), that any variation in the to-beignored member of the stimulus pair would be unrelated to taskstimulus duration, that subjects should "block out" these irrelevant stimuli and concentrate on the task stimulus, and that heart rate would be analyzed to determine how well they concentrated. Subjects were also instructed to maintain fixation on the display panel and avoid unnecessary blinking or movement except during the early intertrial interval (ITI). A sample of 3-4 warned trials was delivered before the experiment to adjust polygraph sensitivity and familiarize subjects with the stimuli. During the experiment proper, duration judgments were communicated via intercom and feedback was given in 2-5 sec via the diode display. Instructions for task reversal were given during a 10-min rest period between experiment halves.

Each half of the experiment was composed of 36 trials. The puff-tone pair was delivered on every trial with orthogonal combinations of short or long puff durations and short or long tone durations. All durations were longer than average peak latency of the integrated EMG response and were selected, from pilot work, to yield approximately $75 \%$ correct performance on each task. In Experiment 1, short and long durations were, respectively, 340 and $480 \mathrm{msec}$ for puff and 90 and $130 \mathrm{msec}(127 \mathrm{msec}$, first four subjects) for tone. In Experiment 2, the respective values were 340 and $473 \mathrm{msec}$ for puff and 118 and $183 \mathrm{msec}(188 \mathrm{msec}$, first four subjects) for tone. On 30 of the 36 trials, onset of the warning buzzer preceded the puff-tone pair by $3 \mathrm{sec}$. Every six trials contained five warned trials and one unwarned trial.

Order of warned and unwarned trials and of the four combinations of long and short durations of tone and puff was determined by a $6 \times 12$ matrix such that unwarned trials occurred twice in each position (first through sixth) of a six-trial set, and over both halves of the experiment the four duration combinations occurred with the same relative frequency within warned and unwarned trials. Each subject of a task-order group began on a different row of, and cycled through, the matrix. The ITIs (26.5, 33.5 , and $40.5 \mathrm{sec}$ onset-to-onset) were randomly assigned, with the restriction that they precede unwarned trials with equal fre- quency and occur equally often in the first and second halves of the matrix.

Following the experiment, the subjects completed forced-choice questions and rating scales concerning their perceptions of task difficulty, stimulus confusions, and arousal state.

\section{Data Analysis}

Rectified EMG was not analyzed statistically. It had been planned to score $R 1$ by detecting peak activity in a window 10 to $25 \mathrm{msec}$ post stimulus onset, but, due to merging of the early and late components on a large proportion of trials, the method appeared to have questionable validity. For illustrative purposes, the initial 35 msec of rectified ipsilateral EMG from Experiment 2 was averaged over trials and subjects, per millisecond per condition. Averages per millisecond per condition were also obtained for the full 250 msec of integrated contralateral EMG of each experiment. For statistical analysis of integrated EMG, onset latency and peak amplitude activity beginning within $21-120 \mathrm{msec}$ after each reflexstimulus onset and peaking no later than $150 \mathrm{msec}$ were scored by a LAP6-W program according to criteria described for potentiometrically measured blink (Graham, Putnam, \& Leavitt, 1975) and modified by Graham, Strock, and Zeigler (Note 1) to achieve comparable identification of the less smooth EMG response. ${ }^{2}$ The percentage of trials excluded by the program equaled $2.4 \%$ (Experiment 1) and 4.3\% (Experiment 2). Frequency of exclusions did not vary as a function of condition except that, in Experiment 1 , the frequency differed significantly between warned $(\mathbf{M}=$ $1.9 \%)$ and unwarned $(M=4.9 \%)$ trials $\left[\chi^{2}(1) ; n=1,728\right.$ trials $)=$ $9.24, \mathrm{p}<.01]$. Acceptable trials without a response were assigned a score of zero for analysis of peak magnitude and were not included in latency analysis. For each subject, magnitude and latency scores were averaged within halves of conditions, that is, for two blocks of 15 warned and two blocks of 3 unwarned trials for each judgment task. $^{3}$ Effects were evaluated by analyses of variance with one between-subjects source-judgment-task order-and three withinsubject sources-attention direction (to vs. away from the reflex stimulus), trial blocks (first vs. second), and warning (warned vs. unwarned).

Heart rate was transformed to beats per minute per 200-msec epoch from the sum of fractional R-R intervals (Graham, 1978), and analyzed for a pretrial period of 11 epochs $(2.2 \mathrm{sec})$ before the time of the warning signal and, separately, for the warning stimulus period of 16 epochs $(3.2 \mathrm{sec})$, that is, for $200 \mathrm{msec}$ before and throughout the foreperiod on warned trials and for the same length of time on unwarned trials. Per subject per epoch means were calculated for halves of conditions, as with EMG, and analyzed for orthogonal components of trend over the epochs in addition to the one between-subject and three within-subject sources analyzed for EMG.

\section{RESULTS}

\section{Blink Reflex}

As predicted, blink EMG bursts tended to be larger and faster when attention was directed toward the reflex-eliciting stimulus than when attention was directed away from it. Differences visible in the averaged integrated EMG (Figure 1) were paralleled by differences in the mean peak magnitude and onset latencies scored per trial (Tables 1 and 2).

The attention direction effect on both magnitude and latency was significant for the acoustic reflex $[F(1,22)=7.51, p<.025$, and $F(1,22)=10.06, p<$ .005 , respectively], but not for the cutaneous reflex. Although none of the interactions of attention direction and warning reached significance, the attention effect was more reliable on warned trials. Separate 


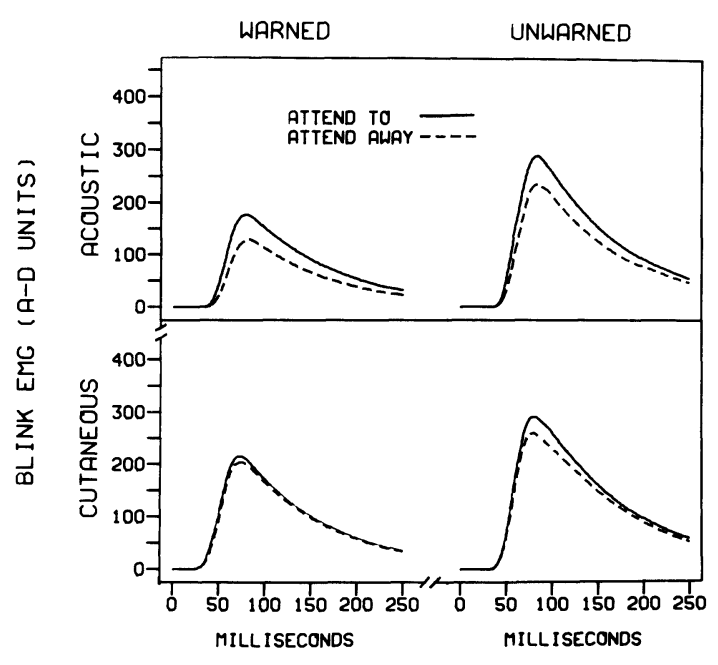

Figure 1. Integrated blink EMG in analog-to-digital units (ADU) as a function of warning and attention direction for Experiment 1, acoustic reflex (upper), and for Experiment 2, late cutaneous reflex (lower).

analyses of warned trials showed a significant effect on magnitude in Experiment $1[\mathrm{~F}(1,22)=6.78, \mathrm{p}<$ $.025]$ and on latency in both experiments $[F(1,22)=$ $9.93, \mathrm{p}<.005$, and $\mathrm{F}(1,22)=5.99, \mathrm{p}<.025$, respectively]. Only magnitude in Experiment 1 was significant on unwarned trials $[F(1,22)=4.97, p<.05]$. In addition, the averaged rectified EMG (Figure 2) suggested a possible selective attention effect on warned trials for R1 magnitude, although, as noted, it could not be tested statistically.

Table 1

Mean Onset Latency for Polysynaptic Blink Reflexes

\begin{tabular}{lccccc}
\hline & \multicolumn{2}{c}{ Warned } & & Unwarned \\
\cline { 2 - 4 } Attend & Block 1 & Block 2 & Block 1 & Block 2 & Mean \\
\hline \multicolumn{5}{c}{ Experiment 1: Acoustic } \\
To & 40.8 & 43.8 & 43.6 & 43.7 & 43.0 \\
Away & 45.1 & 47.2 & 44.5 & 45.5 & 45.6 \\
To & 31.4 & 32.6 & 37.8 & 39.7 & 35.4 \\
Away & 33.2 & 33.7 & 37.9 & 39.0 & 36.0 \\
\hline
\end{tabular}

Note-Three milliseconds were subtracted for integrator delay.

Table 2

Mean Peak Magnitude for Polysynaptic Blink Reflexes

\begin{tabular}{lccccc}
\hline & \multicolumn{2}{c}{ Warned } & & Unwarned \\
\cline { 2 - 3 } Attend & Block 1 & Block 2 & Block 1 & Block 2 & Mean \\
\hline \multicolumn{5}{c}{ Experiment 1: Acoustic } \\
To & 255 & 136 & 363 & 284 & 260 \\
Away & 182 & 99 & 318 & 206 & 201 \\
To & 294 & 197 & 387 & 281 & 290 \\
Away & 282 & 197 & 325 & 275 & 270 \\
\hline
\end{tabular}

Note-Values are in analog-to-digital units.
The selective attention effects were superimposed on a strong nonselective effect of warning such that, whether attention was directed to or away from the reflex stimulus, acoustic blinks and the late cutaneous responses were smaller but $\mathbf{R} 1$ was larger on warned than on unwarned trials (Figures 1 and 2). The magnitude inhibition was reflected in a significant main effect of warning $[F(1,22)=21.36, p<$ .001 and $F(1,22)=13.06, p<.005$, for Experiments 1 and 2, respectively]. Latency of the cutaneous blink was also shortened nonselectively by warning $[\mathrm{F}(1,22)$ $=93.43, \mathrm{p}<.001]$.

There was also significant and nonselective habituation. Independently of attention direction, blinks were smaller and slower on second-trial blocks in both experiments (Tables 1 and 2): for magnitude, the respective values of $F$ equaled 65.90 and 72.88 , and for latency, 12.70 and 5.66. The tendency for the slowing of latency across blocks to be greater on warned than on unwarned trials (Table 2) was significant for acoustic blinks $[F(1,22)=4.70, p<.05]$. Similarly, blink magnitude was smaller on second tasks in both experiments: the respective values of $F$ equaled 16.88 and 64.69 .

\section{Attention Indices}

Heart rate changes during the foreperiod preceding puff-tone pairs (Figures 3A and 3B) did not show the monotonic deceleration seen in previous, similar experiments (Bohlin \& Graham, 1977; Bohlin et al., 1981; Silverstein et al., 1981). Instead, a cubic function with a period of acceleration between initial and final deceleration was observed in both experiments $[F(1,22)=18.90, p<.001$, and $F(1,22)=36.92$, $p<$ .001 , respectively]. The cubic function on warned trials did differ from the cubic function during the equivalent period on unwarned trials, but the effect, significant in Experiment $2[\mathrm{~F}(1,22)=6.10, \mathrm{p}<$ $.025]$, only approached significance in Experiment 1 $[F(1,22)=3.73, p<.07]$.

The heart rate response curve on warned trials tended to change shape as a function of repeated stimulation, being relatively more decelerated just prior to the reflex stimulus on second blocks and tasks. In contrast, the response on unwarned trials had no consistent pattern of change. The only significant effects occurred in Experiment 1 [for epochs $x$ blocks, $F(15,330)=2.73, p<.01$; for epochs $x$ warning $\times$ task 1 vs. task 2 (order group $\times$ attention direction), $\mathrm{F}(15,330)=4.64, \mathrm{p}<.001]$.

Although the anticipatory cardiac changes were not those found in prior research, subjective report and task performance provided evidence that subjects generally attended to the relevant stimuli. On the postexperimental questionnaire, most subjects indicated that they could attend selectively, but 14 subjects agreed that the irrelevant stimulus was "interfering." Of greater importance, performance, 


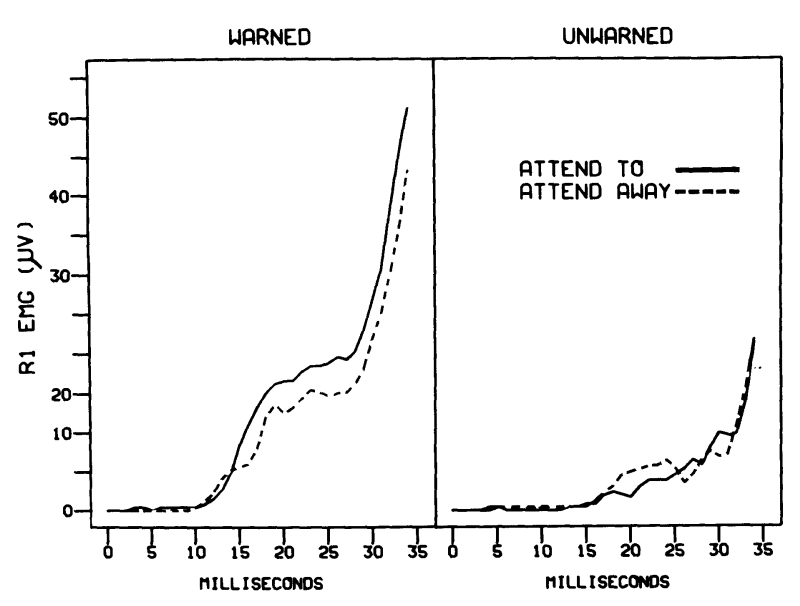

Figure 2. Rectified ipsilateral EMG $(\mu \mathrm{V})$ as a function of warning and attention direction. Activity in the $10-25-\mathrm{msec}$ range is R1; the subsequent higher voltage activity is the beginning of $R 2$.

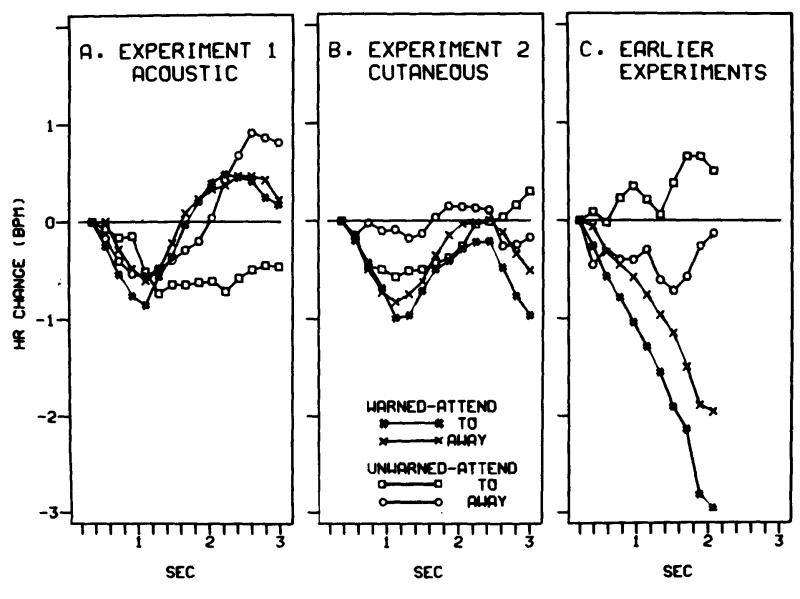

Figure 3. Heart rate changes during the warning interval and equivalent period on unwarned trials in Experiments 1 and 2 and in two earlier experiments: Bohlin and Graham (1977) (attend to) and Silverstein, Graham, and Bohlin (1981) (attend away). Means in beats per minute (BPM) for prewarning period equal 69.8 (Experiment 1), 67.3 (Experiment 2), and 66.48 (earlier experiments).

which averaged $72.7 \%$ and $76.2 \%$ on the puff task and $75.9 \%$ and $78.8 \%$ on the tone task for Experiments 1 and 2, respectively, was better on warned than on unwarned trials and improved with practice. The respective mean percentages correct in Experiments 1 and 2 were 75.8 and 78.1 on warned trials and 67.0 and 72.6 on unwarned trials, with warning effects shown by $F(1,22)=12.12, p<.005$, and $F(1,22)=5.62, p<.05$, respectively. Block effects were also significant in Experiment $1[F(1,22)=6.12$, $\mathrm{p}<.025$ ], with the respective mean percentages correct in Experiments 1 and 2 equal to 71.6 and 74.5 on Block 1 and 77.0 and 79.9 on Block 2.

\section{Arousal Indices}

In neither experiment did the two tasks differ in the level of general arousal, as measured by basal heart rate (Malmo, 1959) during the 2.2-sec period prior to the time of warning stimulus onset, or in difficulty, as measured by performance $(F<1$ in both cases). Similarly, there were no significant differences between tasks on forced-choice selection of the "more difficult" task or in rated arousal state. Arousal did decline over the session, as indicated both by slower heart rate over trial blocks and tasks [significant in Experiment 1 only, $F(1,22)=14.31$, $\mathrm{p}<.005$, and $\mathrm{F}(1,22)=20.45, \mathrm{p}<.001$, respectively] and by rated arousal state, ${ }^{4}\left[\chi^{2}(2 ; \mathrm{n}=10.25), \mathrm{p}<\right.$ .01 , for Experiment 1 , and $\chi^{2}(2 ; n=24)=7.71, p<$ .025 for Experiment 2].

\section{GENERAL DISCUSSION}

The first experiment demonstrated modulation of the acoustic blink reflex as a function of the direction of attention, thus replicating previous work showing changes in blink magnitude, and extending previous findings to show effects on latency as well. Prior work on latency had reported only nonselective facilitation by warning stimuli and had not directly assessed selective modulation as a function of the direction of attention. The latency effect appeared to be as reliable as the magnitude effect. The second experiment suggested that the polysynaptic cutaneous reflex might be similarly modulated by attention direction, although effects were significant only for latency modulation on warned trials.

The possibility of effects on the early R1 component of the cutaneous reflex warrants further investigation. Although merging of the early and late components precluded statistical assessment in our study, the averaged potentials shown in Figure 2 suggest that a selective attention effect might be obtained as early as $15 \mathrm{msec}$. If $R 1$ is a disynaptic reflex in the human, as it apparently is in lower species (Hiraoka \& Shimamura, 1977; Ongerboer de Visser \& Kuypers, 1978), its modulation would necessarily be restricted to preset effects on the receptor, the main sensory trigeminal nucleus, or the facial motor nucleus; if it is trisynaptic, an additional interneuron would be involved. Thus, the possibility exists of confirming or excluding selective effects on a specific synaptic relay.

We have assumed that the selective modulation is a preset attentional effect that acts on the sensory limb of the reflex. The argument for a preset effect is based on the short time between onset of task stimuli and occurrence of the reflex. We assume that any extensive perceptual processing of a stimulus would require a much longer time: evoked potential and cortical stimulation research suggests about $200 \mathrm{msec}$, according to Hillyard, Picton, and Regan (1978, p. 233); a similar value has been obtained in backward masking experiments (Massaro, 1975). Any feedback from such processing would arrive too late to influence these rapid brainstem reflexes. 
Hillyard (1981) and Näätänen (1982, p. 629) rest their arguments for a preset selective mechanism underlying evoked potential modulation on the early onset of such effects, 60-70 msec. ${ }^{5}$ Our finding of modulation of the cutaneous blink as early as $31 \mathrm{msec}$ and of the acoustic blink as early as $\mathbf{4 1} \mathrm{msec}$ argues a fortiori for a preset mechanism. In fact, these values overestimate the onset of selectivity: because our experiments localize the selective bias to a point prior to the convergence of the acoustic and cutaneous reflex pathways, an additional 5-10 msec can be subtracted for conduction time through the common segment.

Our assumption that the preset effect is sensory in nature is supported by three arguments: First, if the duration-judgment task per se influenced nonsensory portions of the reflex arc in different degrees for the auditory and the cutaneous tasks (e.g., because one was more arousing than the other), there would be no basis for predicting a priori which task would be associated with relatively enhanced blinks and which with relatively inhibited ones. A sensory attentional interpretation predicts the direction of such differences. Second, reversal of the direction of modulation when the modalities of the blink-eliciting and the concomitant stimuli were reversed indicates that the preset bias exists prior to convergence of the polysynaptic cutaneous and acoustic blink pathways. This convergence occurs before the facial motornucleus is reached (e.g., Rimpel et al., 1982). Third, although the attention direction $\times$ warning interactions were not significant, separate analyses of warned and unwarned trials indicated that the selective attention effect on blink was more reliable in the focused attention condition than in the diffuse attention condition.

In past work, the argument for a sensory effect has included the evidence that heart rate decelerated monotonically during the warning interval, as illustrated in Figure 3C. Although heart rate change was not solely decelerative in the present study, perhaps due, in part, to our use of a 3-sec rather than a 2-sec interval (Bohlin \& Kjellberg, 1979), the triphasic pattern of deceleration-acceleration-deceleration is common during foreperiods. In any case, the occurrence of both deceleration and acceleration suggests that more than one process was involved. In accord with the Laceys' hypothesis (Lacey, 1967; Lacey \& Lacey, 1970), we assume that deceleration reflects readiness for, or a state of, environmental intake, whereas acceleration indicates environmental rejection, as with aversive stimulation or during cognitive processing, such as mental arithmetic, stimulus transformation, or retrieval from memory. Acceleration may also be associated with motor activity or preparation for motor activity (Chase, Graham, \& Graham, 1968).

The difference in heart rate pattern was associated with another difference between the present and past reflex-modulation research-the finding of a strong nonselective inhibition of blink magnitude by warning. This was evident in both experiments and in a similar earlier experiment (Hackley, 1982; Hackley \& Graham, 1982). Given the better performance on warned trials, it would be difficult to argue that the warning stimulus was not used by the subject, and it seems reasonable to infer, as in the case of heart rate, that it initiated some process other than, or in addition to, attention to intake.

A review of differences between the current experiments and prior reflex-modulation research suggests that a critical variable may be the degree of certainty with which a warning stimulus predicts subsequent stimulation. The initial report of reflex facilitation following warning stimuli (Graham et al., 1975 ) interpreted the effect as due to information provided by the reduction of temporal uncertainty about reflex stimulus occurrence. Other studies in which reflex facilitation has been obtained have also involved uncertainty, either about when the reflex stimulus would occur (Putnam \& Meiss, 1981) or about what the stimulus would be (Bohlin \& Graham, 1977; Bohlin et al., 1981; Ison \& Ashkenazi, 1980), or both types of uncertainty (Anthony, 1981; Bauer, 1982; Bloch, 1972, Experiment 3). In contrast, a warning stimulus had no significant effect on either heart rate or the blink reflex when it predicted a nontask reflex stimulus with certainty (Bloch, 1972, Experiment 1; Brown, 1975, Experiment 2; Sigafus, reported in Graham, 1975). In one additional study, in which the reflex stimulus was a task stimulus predicted with certainty, blinking was inhibited (Brown, 1975, Experiment 3). The Brown study has been the single example of inhibition following warning of a stimulus to which attention has been directed and, as such, has been difficult to explain (Silverstein et al., 1981) because, in the absence of comparison conditions, it was not recognized that the inhibition was nonselective.

Viewed as a function of a certainty-uncertainty variable, the present findings are consistent with the existing literature and strengthen the idea that uncertainty is a psychologically powerful variable. We assume, with Graham et al. (1975), that, when present, uncertainty, like novelty, elicits an involuntary galvanizing of attention or orienting to intake because the environment contains information. We also assume, with Bohlin et al. (1981), that voluntary or anticipatory attention has the same effect on intake as generalized orienting, except that intake enhancement is restricted to a selected channel. The present findings suggest, however, that even a simple discrimination may involve other processes presumably useful in performing the task, such as somatic attenuation of a distracting blink reflex or generation or retrieval of an image of the to-be-discriminated stimuli. Such processes would be nonselective, would 
produce an accelerative heart rate phase, and would produce blink inhibition. The effects of cognitive manipulations on blinking have not been explicitly investigated, but, according to Wagner (1976), retrievalgenerated priming should produce inhibition.

Finally, the present research demonstrated, for the cutaneous reflex, a large nonselective effect on latency that was discordant with the effect on magnitude, that is, a facilitation of the onset time of a reflex whose magnitude was inhibited. Although a nonselective latency effect was not found in the present acoustic experiment, the effect (mean reduction equaled $6.5 \mathrm{msec}$ ) was significant $[\mathrm{F}(1,22)=$ $26.54, \mathrm{p}<.001]$ and was associated with significant reduction of reflex magnitude, in the similar earlier experiment by Hackley (1981). Bohlin et al. (1981) also reported discordant latency and magnitude effects on the acoustic blink reflex.

The fact that selective and concordant latency and magnitude effects are concomitant with nonselective and discordant latency and magnitude effects challenges interpretation by any single physiological mechanism. Presumably any peripheral adjustments acting to alter receptor transduction would have concordant effects, so that the possibility of a "proximal stimulus" explanation of the selective effect cannot be eliminated. Whether the mechanism lies solely within the central nervous system or involves centrally programmed, specific peripheral adjustments, the data support the conclusion that selective directing of attention can bias the sensory pathway at a stage sufficiently early to modulate a brainstem reflex. To conclude that early selectivity is possible is not to imply that it must occur in every situation demanding selective attention. Situations in which it would be easiest to employ a presetting mechanism either to enhance or to filter activity would seem to be those in which the input channel is simply defined and significant stimuli are not expected on other channels. A channel definition in terms of modality is probably the simplest, and the stability of the experimental environment would fulfill the second requirement.

\section{REFERENCE NOTE}

1. Graham, F. K., Strock, B. D., \& Zeigler, B. L. Personal communication, 1979.

\section{REFERENCES}

Anthony, B. J. Probe startle modification during heart rate deceleration: An index of selective anticipation in adults and young children. Unpublished doctoral dissertation, Columbia University, 1981.

Anthony, B. J., \& Graham, F. K. Evidence for sensory-selective set in young infants. Science, 1983, 220, 742-744.

Bauer, L. O. Preparatory modification of the polysynaptic eyeblink reflex. Psychophysiology, 1982, 19, 550. (Abstract)

BLосн, R. M. Inhibition and facilitation effects of a prepulse on the human blink response to a startle pulse. Unpublished doctoral dissertation, University of Wisconsin, 1972.
Boelhouwer, A. J. W. Blink reflexes and preparation. Biological Psychology, 1982, 14, 277-285.

Bohlin, G., \& Graham, F. K. Cardiac deceleration and reflex blink facilitation. Psychophysiology, 1977, 14, 423-430.

Bohlin, G., Graham, F. K., Silverstein, L. D., \& Hackley, S. A. Cardiac orienting and startle blink modification in novel and signal situations. Psychophysiology, 1981, 18, 603-611.

Bohlin, G., \& KJELlBerg, A. Orienting activity in two-stimulus paradigms as reflected in heart rate. In H. D. Kimmel, E. H. van Olst, \& J. F. Orlebeke (Eds.), The orienting reflex in humans. Hillsdale, N.J: Erlbaum, 1979.

Broadbent, D. E. Perception and communication. London: Pergamon Press, 1958.

Brown, J. W. Contingent negative variation and cardiac orienting preceding startle modification. Unpublished doctoral dissertation, University of Wisconsin, 1975.

Chase, W. G., Graham, F. K., \& Graham, D. T. Components of the heart rate response in anticipation of reaction time and exercise tasks. Journal of Experimental Psychology, 1968, 76, 642-648.

Cochran, W. G., \& Cox, G. M. Experimental designs (2nd ed.). New York: Wiley, 1957.

Conover, W. J. Practical nonparametric statistics. New York: Wiley, 1971.

Desmedt, J. E., \& Robertson, D. Differential enhancement of early and late components of the cerebral somatosensory evoked potentials during forced-paced tasks in man. Journal of Physiology (London), 1977, 271, 761-782.

Deutsch, J. A., \& Deutsch, D. Attention: Some theoretical considerations. Psychological Review, 1963, 70, 80-90.

Eason, R. G., OAkLeY, M., \& Flowers, L. Central neural influences on the human retina during selective attention. Physiological Psychology, 1983, 11, 18-28.

Graham, F. K. The more or less startling effects of weak prestimulation. Psychophysiology, 1975, 12, 238-248.

Graham, F. K. Constraints on measuring heart rate and period sequentially through real and cardiac time. Psychophysiology, 1978, 15, 492-495.

Graham, F. K., Putnam, L. E., \& Leavitt, L. A. Lead stimulation effects on human cardiac orienting and blink reflexes. Journal of Experimental Psychology: Human Perception and Performance, 1975, 1, 161-169.

HACKLEY, S. A. Modulation of reflex latency and magnitude by selective attention within subjects. Unpublished master's thesis, University of Wisconsin, 1981.

HaCkLey, S. A., \& Graham, F. K. Modulation of reflex latency and magnitude by selective attention within subjects. Psychophysiology, 1982, 19, 320. (Abstract)

Hilly ARD, S. A. Selective auditory attention and early eventrelated potentials: A rejoinder. Canadian Journal of Psychology, 1981, 35, 85-100.

Hillyard, S. A., Hink, R. F., Schwent, V. L., \& Picton, T. W. Electrical signs of selective attention in the human brain. Science, 1973, 182, 177-180.

Hillyard, S. A., Picton, T. W., \& Regan, D. Sensation, perception, and attention: Analysis using ERPs. In E. Callaway, P. Tueting, \& S. H. Koslow (Eds.), Event related brain potentials in man. New York: Academic Press, 1978.

Hiraoka, M., \& Shimamura, M. Neural mechanisms of the corneal blinking reflex in cats. Brain Research, 1977, 125, 265-275.

Ison, J. R., \& Ashrenazi, B. Effects of a warning stimulus on reflex elicitation and reflex inhibition. Psychophysiology, 1980, 17, 586-591.

Kimura, J. The blink reflex as a test for brain-stem and higher central nervous system function. In J. E. Desmedt (Ed.), New developments in electromyography and clinical neurophysiology (Vol. 3). Basel: Karger, 1973.

LACEY, J. I. Somatic response patterning and stress: Some revisions of activation theory. In M. H. Appley \& R. Trumbull (Eds.), Psychological stress: Issues in research.. New York: Appleton-Century-Crofts, 1967. 
LACey, J. I., \& LACEy, B. C. Some autonomic-central nervous system interrelationships. In P. Black (Ed.), Physiological correlates of emotion. New York: Academic Press, 1970.

Malmo, R. B. Activation: A neuropsychological dimension. Psychological Review, 1959, 66, 367-386.

Massaro, D. W. Experimental psychology and information processing. Chicago: Rand McNally, 1975.

NäÄtÄnen, R. Processing negativity: An evoked-potential reflection of selective attention. Psychological Bulletin, 1982, 92 , 605-640.

NäÄtänen, R., \& Michie, P. T. Early selective attention effects on the evoked potential: A critical review and reinterpretation. Biological Psychology, 1979, 8, 81-136.

Norman, D. A. (1968). Toward a theory of memory and attention. Psychological Review, 75, 522-536.

Ongerboer de Visser, B. W., \& KuYPers, H. G. J. M. Late blink reflex changes in lateral medullary lesions: An electrophysiological and neuroanatomical study of Wallenburg's syndrome. Brain, 1978, 101, 285-294.

Putnam, L. E., \& Meiss, D. A. Reflex inhibition during HR deceleration: Selective attention or motor interference? Psychophysiology, 1980, 17, 324. (Abstract)

Putnam, L. E., \& Meiss, D. A. Reflex blink facilitation during cardiac deceleration: Sensory or motor set? Psychophysiology, 1981, 18, 173. (Abstract)

Rimpel, J., Geyer, D., \& Hopf, H. C. Changes in the blink responses to combined trigeminal, acoustic and visual repetitive stimulation, studied in the human subject. Electroencephalography and Clinical Neurophysiology, 1982, 54, 552-560.

SANes, J. N., \& Ison, J. R. Conditioning auditory stimuli and the cutaneous eyeblink reflex in humans: Differential effects according to oligosynaptic or polysynaptic central pathways. Electroencephalography and Clinical Neurophysiology, 1979, 47, 546-555.

Shahani, B. T., \& Young, R. R. Human orbicularis oculi reflexes. Neurology (Minneapolis), 1972, 22, 149-154.

Silverstein, L. D., \& Graham, F. K. Eyeblink EMG: A miniature eyelid electrode for recording from orbicularis oculi. Psychophysiology, 1978, 15, 377-379.

Silverstein, L. D., Graham, F. K., \& Bohlin, G. Selective attention effects on the reflex blink. Psychophysiology, 1981, 18, 240-247.

Treisman, A. Strategies and models of selective attention. Psychological Review, 1969, 76, 282-299.

Wagner, A. R. Priming in STM: An information-processing mechanism for self-generated or retrieval-generated depression in performance. In T. J. Tighe \& R. N. Leaton (Eds.), Habituation: Perspectives from child development, animal behavior, and neurophysiology. Hillsdale, N.J: Erlbaum, 1976.

\section{NOTES}

1. Recalibration of the sound-level meter suggests that it may have given readings that were too high by $5 \mathrm{~dB}$.

2. The modifications, based on simultaneous recording of potentiometrically measured lid movement and integrated EMG from 24 undergraduate subjects, were: an increase from 12 to $20 \mathrm{ADU}$ in the maximum acceptable baseline shift, from 4 to 10 ADU to define the minimum response, from 70 to $95 \mathrm{msec}$ for the maximum onset to peak latency difference, and from 15 to 25 msec for maximum duration of the response "plateau," that is, the time from peak to beginning of the final return to baseline position.

3. Latency data were missing for an unwarned block for two subjects, and the means were estimated by the chi-square expected value (Conover, 1971). Corrections for the analysis of variance degrees of freedom were not required (Cochran \& Cox, 1957, pp. 302-304).

4. The two adjacent categories of the 4-point scale with the fewest responses were combined, yielding 2 degrees of freedom.

5. Näätảnen's position is not entirely clear. In an earlier paper, Näätänen and Michie (1979) state that $60-70 \mathrm{msec}$ might be too long to necessitate a tonic, preset mechanism. This argument is based on an $\mathrm{H}$-reflex study demonstrating response selection in a visual choice reaction time study within $100-150 \mathrm{msec}$ on the grounds that the acoustic decision in the relevant evoked potential studies could be made even more rapidly. This argument was not retained in the later Näätänen (1982) paper, although he did suggest that selectivity was mediated by contact between incoming stimuli and memory, possibly in secondary sensory areas (p. 629). Hillyard (1981) did not speculate about the neural locus, but indicated that the critical question was whether early modulation of evoked potentials was based on contact between sensory inputs and their memorial representations (possibly late selection) or between sensory inputs and a selection system influenced by memory (early selection).

(Manuscript received August 29, 1983; revision accepted for publication October 24,1983 .) 